\title{
Tratamentos de superfícies de implantes de titânio e zircônia: Revisão de literatura
}

\author{
Surface treatments of titanium and zirconia implants: Literature review \\ Tratamientos superficiales de implantes de titanio y zirconia: Revisión de la literatura
}

Recebido: 13/07/2021 | Revisado: 19/07/2021 | Aceito: 20/07/2021 | Publicado: 28/07/2021

\author{
Ellen Christine Rodrigues de Abreu \\ ORCID: https://orcid.org/0000-0003-2875-5248 \\ Universidade Santo Amaro, Brasil \\ E-mail: ellen_abreu@hotmail.com \\ Débora Serrano de Macedo \\ ORCID: https://orcid.org/0000-0003-2087-8614 \\ Universidade Santo Amaro, Brasil \\ E-mail: deboraserrano.m@gmail.com \\ Sisleide Pejão \\ ORCID: https://orcid.org/0000-0003-4544-0176 \\ Universidade Santo Amaro, Brasil \\ E-mail: sisleide.pejao@gmail.com \\ Paulo Luis Cosimato \\ ORCID: https://orcid.org/0000-0002-0067-0130 \\ Universidade Santo Amaro, Brasil \\ E-mail: paulocosimato@ hotmail.com \\ Wilson Roberto Sendyk \\ ORCID: https://orcid.org/0000-0002-3742-1330 \\ Universidade Santo Amaro, Brasil \\ E-mail: wsendyk@prof.unisa.br \\ Heloisa Fonseca Marão \\ ORCID: https://orcid.org/0000-0002-6128-8576 \\ Universidade Santo Amaro, Brasil \\ E-mail: hfmarao@prof.unisa.br \\ Angélica Castro Pimentel \\ ORCID: https://orcid.org/0000-0002-6317-6439 \\ Universidade Santo Amaro, Brasil \\ E-mail: acpimentel@prof.unisa.br
}

\begin{abstract}
Resumo
Os diferentes tratamentos de superfície sobre os implantes dentários têm a premissa de aprimorar a interface de contato entre osso e implante, acelerando o processo de osseointegração. O objetivo desta revisão de literatura foi verificar os diferentes tipos de tratamentos de superfície dos implantes dentários de titânio e zircônia, suas características e ações sobre a osseointegração. Para isso, foram realizadas pesquisas nas bases de dados nacionais e internacionais: PUBMED, SciELO e Google Scholar. Os dados encontrados demonstram que tanto em implantes de titânio quanto em zircônia, as superfícies podem ser modificadas, com o objetivo de uma melhoria no desempenho biológico acelerando o processo inicial de cicatrização, a fim de promover uma estabilidade inicial superior aos implantes sem tratamento. Ainda, as alterações que promovem uma maior energia de superfície, aumentando a molhabilidade e hidrofilicidade apresentam uma maior adesão e proliferação de osteoblastos e consequentemente uma neoformação óssea mais acelerada, que contribuem para esse processo inicial de cicatrização e osseointegração. Apesar de uma variabilidade nos tipos de tratamento, sendo alguns em comum com o titânio e zircônia, as alterações se mostraram eficazes, permitindo um carregamento em tempos menores. A escolha do tratamento de superfície pode ser determinada pela qualidade óssea, condições sistêmicas do paciente e o tipo de carregamento pré planejado. Em relação aos implantes de zircônia, os estudos são promissores, mas são necessários estudos a longo prazo, pois não há ainda, dados suficientes que indiquem com clareza e segurança a utilização destes implantes, salvo em casos de comprovada alergenicidade ao titânio.
\end{abstract}

Palavras-chaves: Osseointegração; Titânio; Materiais dentários; Implantes dentários.

\begin{abstract}
The different surface treatments on dental implants have the premise of improving the contact interface between bone and implant, accelerating the osseointegration process. The purpose of this literature review was to verify the different types of surface treatments for titanium and zirconia dental implants, their characteristics and actions on osseointegration. For this, researches were carried out in the national and international databases: PUBMED, SciELO and Google Scholar. The data found demonstrate that in both titanium and zirconia implants, the surfaces can be modified, with the aim of improving biological performance by accelerating the initial healing process, in order to
\end{abstract}


promote an initial stability superior to untreated implants. In addition, changes that promote greater surface energy, increasing wettability and hydrophilicity present greater adhesion and proliferation of osteoblasts and, consequently, a more accelerated bone neoformation, which contribute to this initial process of healing and osseointegration. Despite the variability in the types of treatment, some of which are in common with titanium and zirconia, the changes have proven to be effective, allowing loading in less time. The choice of surface treatment can be determined by bone quality, systemic conditions of the patient and the type of pre-planned loading. Regarding zirconia implants, the studies are promising, but long-term studies are necessary, as there is not yet enough data to clearly and safely indicate the use of these implants, except in cases of proven allergenicity to titanium.

Keywords: Osseointegration; Titanium; Dental materials; Dental implants.

\section{Resumen}

Los diferentes tratamientos superficiales sobre implantes dentales tienen como premisa mejorar la interfaz de contacto entre hueso e implante, acelerando el proceso de osteointegración. El propósito de esta revisión de la literatura fue verificar los diferentes tipos de tratamientos superficiales para implantes dentales de titanio y zirconio, sus características y acciones sobre la osteointegración. Para ello, se realizaron investigaciones en las bases de datos nacionales e internacionales: PUBMED, SciELO y Google Scholar. Los datos encontrados demuestran que tanto en implantes de titanio como de zirconia, las superficies pueden modificarse, con el objetivo de mejorar el rendimiento biológico acelerando el proceso de cicatrización inicial, con el fin de promover una estabilidad inicial superior a los implantes no tratados. Además, los cambios que promueven una mayor energía superficial, aumentando la humectabilidad y la hidrofilicidad presentan una mayor adhesión y proliferación de osteoblastos y, en consecuencia, una neoformación ósea más acelerada, que contribuyen a este proceso inicial de cicatrización y osteointegración. Apesar de la variabilidad en los tipos de tratamiento, algunos de los cuales son comunes con el titanio y la zirconia, los cambios han demostrado ser efectivos, permitiendo la carga en menos tiempo. La elección del tratamiento de superficie puede determinarse por la calidad ósea, las condiciones sistémicas del paciente y el tipo de carga planificada previamente. En cuanto a los implantes de zirconia, los estudios son prometedores, pero son necesarios estudios a largo plazo, ya que aún no hay datos suficientes para indicar de forma clara y segura el uso de estos implantes, salvo en los casos de alergenicidad demostrada al titanio.

Palabras clave: Osteointegración; Titanio; Materiales dentales; Implantes dentales.

\section{Introdução}

No planejamento de uma reabilitação oral com implantes, o primeiro e essencial resultado é a osseointegração. Esta ocorre inicialmente com a estabilidade primária, no momento da instalação do implante e está relacionada à resistência mecânica do implante no alvéolo preparado. Posteriormente, segue-se a estabilidade secundária que é a capacidade do implante em se manter estável após a deposição e regeneração do tecido vivo peri-implantar, através do processo de remodelação óssea, associada a distribuição de cargas oclusais (Dagher et al., 2014). Todo esse processo citado, é dependente de fatores, tais como a macro e microgeometria do implante, assim como a qualidade óssea do paciente, planejamento e habilidade do cirurgiãodentista.

As alterações micro ou nanométricas sobre as superfícies dos implantes, têm sido amplamente estudadas, pois atuam acelerando o processo inicial de cicatrização óssea, levando a uma estabilidade biomecânica mais precoce. Essas alterações são importantes tanto para a diferenciação e adesão dos osteoblastos durante a fase inicial de osseointegração, quanto para a fase de remodelação óssea em um segundo momento (Gil et al., 2016; Smeets et al., 2016).

O comportamento biológico do titânio, por si só, já proporciona ao implante biocompatibilidade, força e capacidade de osseointegração. Essas características tornaram-no padrão ouro de material de eleição para confecção de implantes odontológicos. Atualmente ele é associado a diferentes tipos de tratamentos de superfície com o intuito de acelerar o processo de cicatrização e permitir carregamentos precoces (T. Albrektsson et al., 1981, 2005; Steinemann, 1998).

No entanto, na última década, houve um aumento no uso de implantes de zircônia, mais especificamente a zircônia tetragonal policristalina estabilizada com ítrio (Y-TZP), pois apresenta ótimas propriedades biomecânicas, estabilidade química, radiopacidade e elevado potencial de osseointegração, além de apresentar uma menor adesão bacteriana (Hochscheidt et al., 2012; Karthigeyan et al., 2019; Schünemann et al., 2019). Sua similaridade de cor aos dentes naturais, é uma vantagem sobre o titânio, sendo indicado em áreas estéticas e em pacientes com biotipo gengival fino e linha de sorriso alta (Gahlert et 
al., 2012, 2016). A indicação dos implantes de zircônia pode não ser somente para áreas estéticas, pois Oliva et al., afirmaram que pacientes com problemas de pele ou doenças autoimunes, apresentam maior risco de alergias ao metal e que essa sensibilidade pode ocorrer a longo prazo (Oliva et al., 2010).

Tanto nos implantes de titânio quanto em zircônia, as superfícies podem ser modificadas, objetivando uma melhoria no desempenho biológico do implante, sem alterar as propriedades de cada material, alterando a rugosidade da superfície e/ou aplicando-se revestimentos bioativos (Bormann et al., 2012; Karthigeyan et al., 2019). Essas modificações criam uma união bioquímica, capaz de acelerar as fases iniciais de formação do tecido ósseo (Rosifini et al., 2011).

Assim, o objetivo deste estudo foi realizar uma revisão de literatura dos tipos de tratamento de superfície dos implantes dentários de titânio e zircônia, suas características e ações sobre a osseointegração.

\section{Metodologia}

Trata-se de um estudo de revisão da literatura (Pereira et al., 2018; Koche, 2011) sobre os mais diversos tipos de modificações de superfícies de implantes dentários, apresentando as principais informações e características dos tratamentos de superfície. Para isso, foram realizadas pesquisas nas bases de dados nacionais e internacionais: PUBMED, SciELO e Google Scholar.

\section{Revisão de Literatura}

\subsection{Osseointegração}

Alguns fatores são essenciais para ocorrer a osseointegração, tais como: a escolha do material do implante, design do implante, superfície do implante, o tipo de tecido ósseo, a técnica cirúrgica e a carga aplicada.(T. Albrektsson et al., 1981). As modificações de superfície foram sugeridas com o intuito de acelerar o processo de osseointegração dos implantes e, assim, obter um melhor contato entre o osso e o implante (Wennerberg et al., 1996).

Segundo De Souza et al., devido ao contato íntimo com tecidos biológicos no local da implantação, a superfície do material é um fator crítico para a determinação do processo de biocompatibilidade e osseointegração. Os eventos biológicos na interface osso-implante são influenciados por várias características do implante, como composição química, energia superficial e topografia (Souza et al., 2020). Essas alterações podem modificar as respostas celulares, principalmente de osteoblastos, na adsorção de células na superfície, na atividade da fosfatase alcalina e da osteocalcina, impedindo a interposição de camadas proteicas amorfas, acelerando a osseointegração, e consequentemente a estabilidade secundária (Costa et al., 2005).

Os processos de tratamento de superfícies dos implantes, podem aumentar a área de contato e a energia superficial da superfície e estes podem ser por subtração ou adição, nas quais são geradas superfícies rugosas e/ou porosas. Quanto ao tipo de tratamento dado à superfície, podem ser físico, químico ou uma associação das técnicas (Tabela 1)(Guimarães Neto \& Binder, 2019; Jemat et al., 2015). 
Tabela 1: Tipos de tratamento de superfícies.

\begin{tabular}{|c|c|c|}
\hline Tipo de tratamento & Método & Descrição \\
\hline Usinada & Físico & $\begin{array}{l}\text { Superfície hidrofóbica; pequenas ranhuras provenientes do } \\
\text { processo de usinagem; não indutora; anisotrópica; rugosidade entre } \\
0,5 \mu \mathrm{m} \text { e } 0,1 \mu \mathrm{m} \text {. }\end{array}$ \\
\hline Ataque-ácido & Químico; subtração & $\begin{array}{l}\text { Limpam a superfície e alteram a rugosidade; ácidos mais } \\
\text { utilizados: fluorídrico ( } \mathrm{HF}) \text {, nítrico }\left(\mathrm{HNO}_{3}\right) \text { e sulfúrico }\left(\mathrm{H}_{2} \mathrm{SO}_{4}\right) \text {; } \\
\text { aumentam a adesão celular. Podem ser utilizados em combinação, } \\
\text { geralmente o ácido sulfúrico com o hidroclorídrico (dupla ataque- } \\
\text { ácido). }\end{array}$ \\
\hline Plasma spray & Físico-químico; adição & $\begin{array}{l}\text { Aderência de partículas aquecidas de } \mathrm{HA} \text { ou Ti, através do } \\
\text { aquecimento de gás de argônio (entre } 10.000 \text { a } 30.000 \mathrm{C}^{\circ} \text { ), } \\
\text { lançadas em alta velocidade; aspecto de lava vulcânica após } \\
\text { resfriamento e solidificação, formando as rugosidades. }\end{array}$ \\
\hline Jateamento & Físico; subtração & $\begin{array}{l}\text { Projeção pressurizada de partículas, que podem ser: sílica, areia, } \\
\text { hidroxiapatita, alumina, titânio; partículas residuais removidas com } \\
\text { ataque-ácido; a rugosidade depende do tamanho das partículas, do } \\
\text { tempo e da pressão do disparador. }\end{array}$ \\
\hline Anodização & Físico-químico; adição & $\begin{array}{l}\text { Adição de camada de óxido de titânio }\left(\mathrm{TiO}_{2}\right) \text { sobre a já existente } \\
\text { no implante, através de ativação de íons; }\end{array}$ \\
\hline Laser & Físico; subtração & $\begin{array}{l}\text { Modificação por irradiação por feixes laser; alto grau de pureza, } \\
\text { por não envolver elementos químicos; rugosidades com tamanhos } \\
\text { e formas variadas, dependendo da intensidade do pulso da fonte } \\
\text { emissora; micro retenções regularmente orientadas, devido ao } \\
\text { controle sobre a angulação das rugosidades. }\end{array}$ \\
\hline Biomimético & Físico-químico; adição & $\begin{array}{l}\text { Recobrimento da superfície com camada uniforme de } \\
\text { hidroxiapatita, similar à camada biológica, com até } 15 \mu \mathrm{m} \text { de } \\
\text { espessura. (precipitação heterogênea de fosfato de cálcio sob } \\
\text { condições fisiológicas de temperatura e } \mathrm{pH} \text { sobre o implante } \\
\text { dentário, por meio da utilização de solução de íons semelhantes ao } \\
\text { plasma sanguíneo com vistas à deposição de camada de apatita). }\end{array}$ \\
\hline
\end{tabular}

Fonte: Autores.

Os processos de subtração são aqueles que retiram uma camada da superfície, como por exemplo o processo de jateamento, ataque ácido e a modificação a laser. Os processos de adição são caracterizados pela deposição de uma camada que podem produzir sobre essa superfície, porosidades e rugosidades. Características estas que influenciarão na camada de óxido que será produzida. Ainda, pode-se ter a associação de dois tipos de tratamento sobre a mesma superfície (Tomas Albrektsson \& Wennerberg, 2019; Jemat et al., 2015).

Processos como a usinagem, jateamento, ataque ácido, entre outros, são descritos também como modificações sobre os implantes de zircônia, com o mesmo intuito de modificar a topografia da superfície e, consequentemente, melhorar a osseointegração (Gahlert et al., 2007; Sennerby et al., 2005). Apesar destes citados serem os mais comuns comercialmente, e praticamente idênticos às modificações sobre o titânio, a literatura demonstra que há estudos com outros tipos de tratamentos sobre a superfície de zircônia, como a aplicação de luz ultravioleta, infiltração ácido seletiva, self-assembly (automontagem) e alguns outros tipos de revestimentos, que ainda estão em estudo (Karthigeyan et al., 2019; Schünemann et al., 2019). 


\subsection{Implantes usinados}

Implantes usinados simplesmente se referem ao processo de fabricação, onde o titânio é transformado, polido ou fresado (Figura 1A e 1B) (Esposito et al., 2014). Segundo Misch, os implantes usinados passavam apenas por um processo de descontaminação após a usinagem, e eram caracterizados por superfícies lisas ou maquinadas. No entanto observou-se microscopicamente uma aspereza devido a presença de ranhuras e sulcos, produzidos pelo processo de usinagem. Nessas ranhuras ou rugosidades formadas, começou-se a observar uma neoformação óssea em direção a essas rugosidades, características de uma osteogênese a distância (Misch, 2011). Mas essas ranhuras não têm a capacidade de tornar a superfície indutora e são consideradas de extrema importância para o processo de adesão celular e produção de matriz proteica. Os implantes usinados têm um valor médio de rugosidade de superfície entre 0,53 e $0,96 \mu \mathrm{m}$, mas esse tipo de superfície não recebe tratamento químico ou mecânico, apresentando apenas macro morfologia de usinagem. Ainda, os processos de limpeza e desinfecção podem alterar a energia de superfície do implante usinado, tornando-a mais atrativa para adesão celular (Carvalho et al., 2009).

Figura 1: Microscopia de implantes com diferentes tratamentos de superfície. (A) Liga de Ti polida com carboneto de silício (granulação 1200), magnificação original x800. (B) Ti usinado, magnificação original x500. (C) Ti pulverizado com plasma,

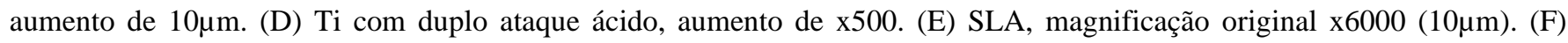
SLActive ${ }^{\circledR}$, aumento de $5 \mu \mathrm{m}$.
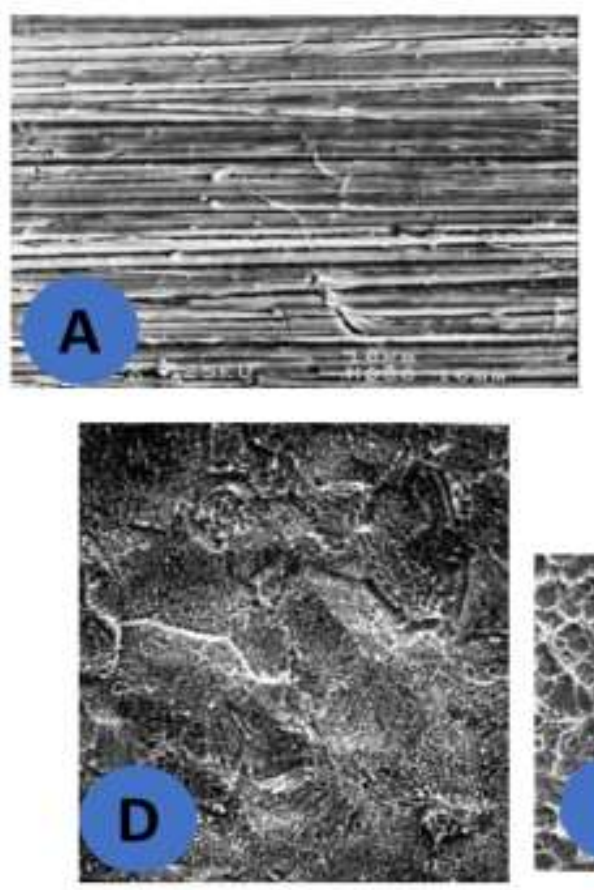
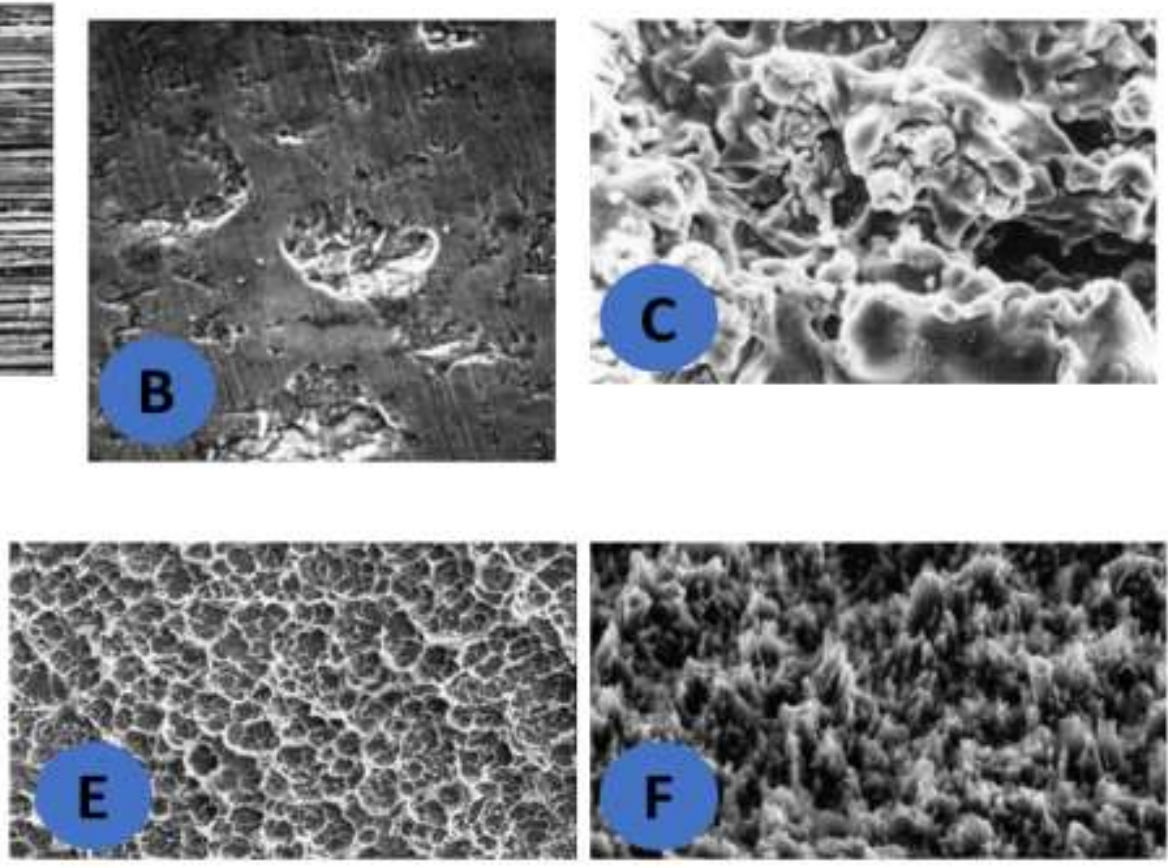

Fonte: Jemat et al. (2015).

\subsection{Processos de subtração}

\subsubsection{Ataque ácido}

As superfícies tratadas com ataque ácido aumentam a adesão celular e formação óssea, melhorando a osseointegração. Os mais utilizados são o ácido fluorídrico (HF), ácido nítrico $\left(\mathrm{HNO}_{3}\right)$ e ácido sulfúrico $\left(\mathrm{H}_{2} \mathrm{SO}_{4}\right)$ ou uma combinação deles, e tem por finalidade limpar a superfície e alterar a rugosidade em microescala, tanto na superfície do titânio quanto na zircônia. 
O desgaste homogêneo independe do tamanho e formato do implante, mas a alta concentração do ácido, temperatura e tempo de tratamento interferem na quantidade de material removido da superfície. Por não haver pressão, não há risco de delaminação do material, mas pode ocorrer a formação de bordas afiadas que podem ser suavizadas com um tratamento térmico. No entanto, a desvantagem do condicionamento ácido é que ele pode causar alterações químicas indesejáveis (Jemat et al., 2015; Karthigeyan et al., 2019).

O duplo ataque ácido que é a combinação de dois ácidos para remover e posteriormente estabilizar a camada de óxido, e é considerado um método de alteração de superfície seguro e eficaz, sendo as misturas de $\mathrm{HNO}_{3}$ e $\mathrm{HF}$ ou uma mistura de ácido clorídrico ( $\mathrm{HCl}$ ) e $\mathrm{H}_{2} \mathrm{SO}_{4}$, as mais utilizadas (Figura 1D). Esses ácidos apresentam a capacidade de promover rugosidades na superfície dos implantes, além de aumentar a energia de superfície, proporcionando uma maior molhabilidade e absorção de proteínas. Isso acelera o processo de osseointegração, e permite a reabilitação protética em tempos menores. Ainda, apresenta uma vantagem em comparação a outros métodos que é a de evitar a possibilidade de contaminação da superfície por partículas abrasivas ou a delaminação de uma camada anodizada (Tomas Albrektsson \& Wennerberg, 2019; Barfeie et al., 2015; Silva et al., 2016).

\subsubsection{Jateamento}

O jateamento é a projeção pressurizada de partículas de materiais cerâmicos ou outros materiais, como a sílica, areia, $\mathrm{HA}$ (hidroxiapatita), alumina e o $\mathrm{TiO}_{2}$ (dióxido de titânio), seguido de um ataque ácido para remover as partículas residuais. As rugosidades dependem do tamanho das partículas, do tempo e da pressão do disparador (Jemat et al., 2015).

\subsubsection{Jateamento associado ao ataque-ácido}

Esse tipo de modificação promove alterações físicas (rugosidades) e químicas (energia de superfície) sobre a superfície do implante, produzindo uma melhor osseointegração durante a fase de cicatrização devido ao aumento da área de contato, o que aumenta a superfície disponível para um novo crescimento ósseo, melhorando a fixação mecânica (VelascoOrtega et al., 2019). A superfície SLA (Sandblasted, Large-grit and Acid etching), segue este preceito. Segundo Galan Jr, as superfícies são tratadas com partículas de $\mathrm{Al}_{2} \mathrm{O}_{3}$, com tamanho aproximado de 250 a $500 \mu \mathrm{m}$, com o intuito de criar macro rugosidades, seguido de duplo ataque ácido (ácido hidrofluorídrico $1 \%$ + ácido nítrico 30\%) para formação de micro rugosidades na superfície do implante (Figura 1E). A empresa Straumann ${ }^{\circledR}$ (Straumann Dental Implants; Institut Straumann AG, Basel, Switzerland), ainda acrescentou ao seu portfólio a superfície SLActive ${ }^{\circledR}$, onde, além do jateamento seguido do ataque ácido, o implante é armazenado em solução isotônica de cloreto de sódio $0,9 \%(\mathrm{NaCl})$, que quando em contato com o sangue gerado durante a fresagem do implante, apresenta hidrofilicidade e com alto grau de molhamento (Figura 1F). A superfície é hidroxilada e essa mudança química melhora as estruturas superficiais, que são ideais para a adsorção de proteínas e para promover a intenção imediata do implante ao tecido ósseo. A superfície SLActive ${ }^{\circledR}$ foi desenvolvida para otimizar a estabilidade do implante em menor tempo de osseointegração e diminuir os riscos de perda de implantes nas fases iniciais da osseointegração (Chambrone et al., 2015; Galan Jr \& Vieira, 2013, Roccuzzo \& Wilson Jr, 2008; Şener-Yamaner et al., 2017).

\subsubsection{Superfície tratada a laser}

A alteração de superfície por meio do uso de laser tem a vantagem de não envolver diferentes elementos químicos, assim não contaminando a camada de óxidos. Outra vantagem que esse tipo de modificação apresenta, é o controle sobre a angulação das rugosidades produzidas, que cria micro retenções regularmente orientadas na superfície do implante. As rugosidades podem ter tamanhos e formas variadas, dependendo da intensidade do pulso da fonte emissora. Vários são os tipos de laser que podem ser utilizados para este processo. Um dos lasers utilizado é o de diodo, que é um tipo comum de laser 
semicondutor, já que consiste em um transdutor que transforma energia elétrica em fótons (Berardi et al., 2011; Gaggl et al., 2000; Richardson et al., 2010).

Jemat et al., compararam estudos relacionando o torque de remoção de implantes com superfícies modificadas por laser, usinadas e jateadas. Encontraram resultados superiores nas modificações a laser, podendo chegar a $52 \mathrm{~N}$ em comparação a 35N nas superfícies usinadas, em um período de 12 semanas de cicatrização.

Ainda, outros autores, enfatizam que somente o tratamento a laser, não é suficiente para se obter uma superfície ideal à osseointegração e que outros métodos devem ser combinados (Carvalho et al., 2009; Silva et al., 2016).

\subsection{Processos de adição}

\subsubsection{Tratamento Biomimético - Hidroxiapatita}

Quando exposto ao ar, o titânio (Ti) forma imediatamente uma camada de óxido com uma espessura de 2 a $10 \mathrm{~nm}$ que promove resistência à corrosão. A camada de dióxido de titânio (TiO2) ou camada biológica é responsável pela adaptação íntima entre o osso mineralizado e a superfície do implante (Galan Jr \& Vieira, 2013).

$\mathrm{O}$ tratamento biomimético, consiste no recobrimento da superfície do implante com uma camada uniforme de hidroxiapatita (HA) similar à camada biológica com até $15 \mu \mathrm{m}$ de espessura. Ocorre por meio da precipitação heterogênea de fosfato de cálcio, sob condições fisiológicas de temperatura e $\mathrm{pH}$, sobre a superfície do implante dentário. Utiliza-se uma solução de íons semelhantes ao plasma sanguíneo com o objetivo de se depositar uma camada de apatita biológica (Silva et al., 2016). A hidroxiapatita apresenta alta biocompatibilidade, combinando assim, as vantagens mecânicas dos metais, com a excelente biocompatibilidade e bioatividade da HA (Abe et al., 1990).

As moléculas integradas à estrutura do material são liberadas gradualmente, sendo capazes de aumentar a osteocondutividade e potencializar a formação do osso em torno do implante. O fosfato de cálcio, apresenta-se como um biomaterial para reposição e regeneração do tecido ósseo, pois apresenta excelente propriedade de biocompatibilidade, bioatividade, ausência de toxicidade, taxas de degradação variáveis e osteocondutividade. Além disso, as moléculas biologicamente ativas, como agentes osteogênicos, podem ser precipitadas como componentes inorgânicos para formar uma matriz com propriedades osteocondutoras (camada de fosfato de cálcio) potencializando a osseointegração (Bernardes et al., 2012; Carvalho et al., 2009; Silva et al., 2016).

Rosifini et al., afirmam que este método é atrativo para melhorar a qualidade da interface osso-implante, principalmente nos períodos iniciais da cicatrização. Ainda, cita que há vantagens em relação aos demais métodos de tratamento de superfície, tais como: baixo custo, deposição em implantes com qualquer geometria, processamento em baixas temperaturas, com possibilidade de utilização no revestimento de materiais sensíveis à temperatura, tais como os polímeros e que a união química do revestimento ao substrato apresenta uma camada uniforme e retentiva, com possibilidade de incorporar moléculas orgânicas (proteínas) aos cristais formados (Rosifini et al., 2011).

\subsubsection{Plasma Spray de HA e Ti}

Esse tipo de tratamento é realizado utilizando-se um gás de argônio aquecido entre 10.000 e $30.000^{\circ} \mathrm{C}$ e partículas aquecidas do material de recobrimento (Ti ou HA), que são lançadas em altas velocidades contra o corpo do implante (Figura 1C). Após o contato, as partículas resfriam e solidificam-se, e a superfície adquire um aspecto de lava vulcânica solidificada. A técnica de plasma-spray é empregada para aplicar Ti ou HA, formando rugosidades devido à aderência dessas partículas à superfície do implante. A espessura formada após o tratamento, pode variar de 10 a $40 \mu \mathrm{m}$ quando aplicado o titânio e de 50 a $70 \mu \mathrm{m}$ quando em hidroxiapatita (Carvalho et al., 2009). 
O plasma spray de HA e Ti, está em desuso. Segundo Carvalho et al., o deslocamento da HA da superfície do implante, causado por falhas de adesividade, podem induzir uma osteólise causando uma diminuição das propriedades biomecânicas, principalmente na fixação entre osso/implante, levando a falha da reabilitação. O mesmo acontece com o plasma spray de Ti, pois segundo Sadowski, há achados de acúmulos de partículas em linfonodos regionais, pulmão e ossos em pacientes com implantes com esse tipo de tratamento de superfície (Carvalho et al., 2009; Sadowsky, 2020).

Atualmente, há implantes utilizando partículas nanométricas de HA $\left(\mathrm{HAnano}^{\circledR}\right)$ sobre a sua superfície (Bezerra et al., 2015).

\subsubsection{Anodização}

A anodização promove um aumento da camada de óxido, já existente sobre a superfície do implante de Ti. Esta, é obtida quando o implante é usado como um ânodo, que ativa íons quando um potencial elétrico é aplicado e assim ocorrem reações de transferência de cargas de íons e consequentemente o aumento da espessura de TiO2 sobre a superfície do implante. $\mathrm{O}$ aumento dessa camada de óxido de titânio e a adição de outros elementos, como fosfato $\left(\mathrm{PO}_{4}\right)$, potencializa a osseointegração. A resistência à corrosão e a biocompatibilidade estão relacionadas à presença de uma camada de óxido não reativo, o que impede a formação de tecido fibroso em volta do implante e cria um contato direto com o tecido ósseo (Guimarães Neto \& Binder, 2019; Silva et al., 2016). Esse tipo de tratamento altera a topografia e composição da superfície, pois além de aumentar a camada de óxido (de 17 - 200nm para $600-1000 \mathrm{~nm}$ ), altera a rugosidade e aumenta a área de superfície, que consequentemente aumenta a adesão de células osteoblásticas (Barfeie et al., 2015).

Degidi et al., realizaram um estudo de acompanhamento de dez anos de implantes carregados imediatamente com superfícies anodizadas porosas e relataram uma taxa de sucesso cumulativa de 65,26\% e taxa de sobrevivência de 97,96\%, associado a uma boa higiene oral (Degidi et al., 2012).

\subsection{Implantes em zircônia}

Apesar do crescimento da utilização da zircônia (Y-TZP) em implantes dentais e suas características favoráveis à osseointegração como já citamos, a utilização destes implantes ainda não é rotina na prática odontológica, pois se a indicação para a sua utilização for a estética, como em casos de biotipo gengival fino, o abutment em zircônia acaba por resolver essa questão. No entanto, as pesquisas com esse material e alterações na macro e microgeometria estão sendo amplamente estudadas.

Nesta revisão de literatura, encontramos algumas modificações sobre a superfície dos implantes de zircônia igualmente aplicados à superfície dos implantes de titânio, assim como algumas modificações que não estão ainda em aplicações comerciais, mas com resultados promissores. A Tabela 2 apresenta os diversos tratamentos de superfície relatados na literatura e suas características. 
Tabela 2: Tipos de tratamento de superfície em zircônia.

\begin{tabular}{|c|c|c|}
\hline $\begin{array}{c}\text { Tipo de } \\
\text { tratamento }\end{array}$ & Método & Descrição \\
\hline Polimento & Físico; subtração & $\begin{array}{l}\text { Utiliza-se papel de polimento de carboneto de silício e suspensão de } \\
\text { diamante ou sílica em uma máquina de polimento. Altera a topografia, sem } \\
\text { modificar a química da superfície. Rugosidade varia de } 8 \text { a } 200 \mu \mathrm{m} \text {. }\end{array}$ \\
\hline Ataque-ácido & Químico; subtração & $\begin{array}{l}\text { Limpam a superfície e alteram a rugosidade; ácidos mais utilizados: } \\
\text { fluorídrico }(\mathrm{HF}) \text {, nítrico }\left(\mathrm{HNO}_{3}\right) \text { e sulfúrico }\left(\mathrm{H}_{2} \mathrm{SO}_{4}\right) \text {; aumentam a adesão } \\
\text { celular. Não causa delaminação, mas pode causar alterações químicas } \\
\text { indesejáveis. Podem ser associados. }\end{array}$ \\
\hline $\begin{array}{l}\text { Infiltração ácida } \\
\text { seletiva }\end{array}$ & Físico; adição & $\begin{array}{l}\text { Revestimento da superfície com vidro de infiltração específico, aquecido } \\
\text { acima da temperatura de transição vítrea; superfície nanoporosa; química da } \\
\text { superfície inalterada; vestígios removidos com ácido fluorídrico } 5 \%\end{array}$ \\
\hline Laser & Físico; subtração & $\begin{array}{l}\text { Modificação por irradiação por feixes laser de } \mathrm{CO} 2 \text {; sem contaminação por } \\
\text { não ter contato entre o laser e a superfície da zircônia. Alterações da } \\
\text { superfície melhoram a molhabilidade }\end{array}$ \\
\hline Biomimético & Físico-químico; adição & $\begin{array}{l}\text { Imobilização de biomoléculas na superfície. Arginina-glicina-aspartato } \\
\text { (RGD) utilizado como peptídeo adesivo; RGD imobilizado sobre a Y-TZP, } \\
\text { aumenta a biocompatibilidade. }\end{array}$ \\
\hline Plasma-Spray & Físico; adição & $\begin{array}{l}\text { Revestimento de hidroxiapatita revestida com zircônia estabilizada com ítrio } \\
\text { (YSZ). }\end{array}$ \\
\hline Luz ultravioleta & Físico-químico & $\begin{array}{l}\text { Induz excitação de elétrons, aumentando a energia de superfície da zircônia, } \\
\text { resultando em uma super hidrofilicidade, devido ao aumento da } \\
\text { molhabilidade. Contato osso/implante altamente aprimorado devido a } \\
\text { interação inicial com proteínas e células que beneficiam o processo inicial } \\
\text { de cicatrização e osseointegração. }\end{array}$ \\
\hline Self-Assembly & Químico; adição & $\begin{array}{l}\text { Técnica usada para formar multicamadas nanométricas, com base em } \\
\text { interações complementares entre polieletrólitos carregados de forma } \\
\text { diferente, sendo a atração eletrostática a força principal. Ocorre a adsorção } \\
\text { de um revestimento ativo orgânico sobre uma superfície sólida (Mastrangelo } \\
\text { et al., 2011; Shi et al., 2017) }\end{array}$ \\
\hline
\end{tabular}

Fonte: (Karthigeyan et al., 2019); (Schünemann et al., 2019).

Os implantes de zircônia e titânio usinados apresentam valores de BIC semelhantes (Hafezeqoran \& Koodaryan, 2017), mas em relação a adesão microbiana, a literatura afirma que ensaios microbiológicos revelam um menor número de bactérias sobre a superfície de zircônia e isso pode ser confirmado no estudo de Roehling et al., que avaliaram a formação de biofilme oral in vitro sobre as duas superfícies ( $\mathrm{Ti}$ e $\mathrm{Zr}$ ). Encontraram uma redução significativa na massa de biofilme sobre os discos de zircônia, tanto nos usinados quanto nos jateados (Roehling et al., 2017).

O simples processo de polimento da superfície do implante de zircônia, já resulta em rugosidades que variam de 8 a 200nm (correspondentes a 0,008 e 0,2 $\mu \mathrm{m}$ ). Segundo Karthigeyan et al., isso proporciona melhor adesão de fibroblastos sem alterar a superfície química, além de contribuir para a limpeza da superfície (Karthigeyan et al., 2019).

A superfície ZLA (Straumann ${ }^{\circledR}$ Pure Ceramic ZLA ${ }^{\mathrm{TM}}$ ), segue o mesmo princípio da SLA, que é o jateamento seguido por duplo ataque-ácido, mas feita sobre a superfície do implante de zircônia, assim temos uma associação dos benefícios apresentados pela zircônia com uma modificação de superfície já bem estabelecida na literatura (Barfeie et al., 2015; Gahlert et al., 2016).

A superfície de zircônia também pode ser modificada por laser, sendo o de $\mathrm{CO}_{2}$ um dos mais utilizado. Este tipo de modificação diminui a rugosidade, mas aumenta a energia superficial e consequentemente a molhabilidade e aderência de 
osteoblastos. Além disso, o tratamento a laser não apresenta risco de contaminação da superfície, pois não há contato com a superfície do material. A maior hidrofilicidade é biologicamente mais atraente para a proliferação de osteoblastos, adsorção de proteínas e osseointegração, e essa característica pode ser observada neste tipo de tratamento. Isso também pode ser observado quando a superfície é tratada com luz ultravioleta, que aumenta a energia superficial a ponto de promover uma super hidrofilicidade aprimorando o contato osso/implante, beneficiando o processo inicial de cicatrização e osseointegração (Karthigeyan et al., 2019; Schünemann et al., 2019).

Revestimentos bioativos desenvolvidos para a superfície de zircônia, aumentam a biocompatibilidade, bioatividade e potencial antibacteriano, e ainda tem a capacidade de induzir a formação de hidroxiapatita em um ambiente biológico, que é essencial à neoformação óssea. Estes revestimentos podem ser de sílica, magnésio, nitrogênio, carbono, fosfato de cálcio hidroxiapatita, dopamina e grafeno, como citado por Schünemann et al. (Figura 2).

Figura 2: Revestimentos de zircônia mostrando vantagens biológicas em termos de bioatividade, osseointegração e efeitos antibacterianos.

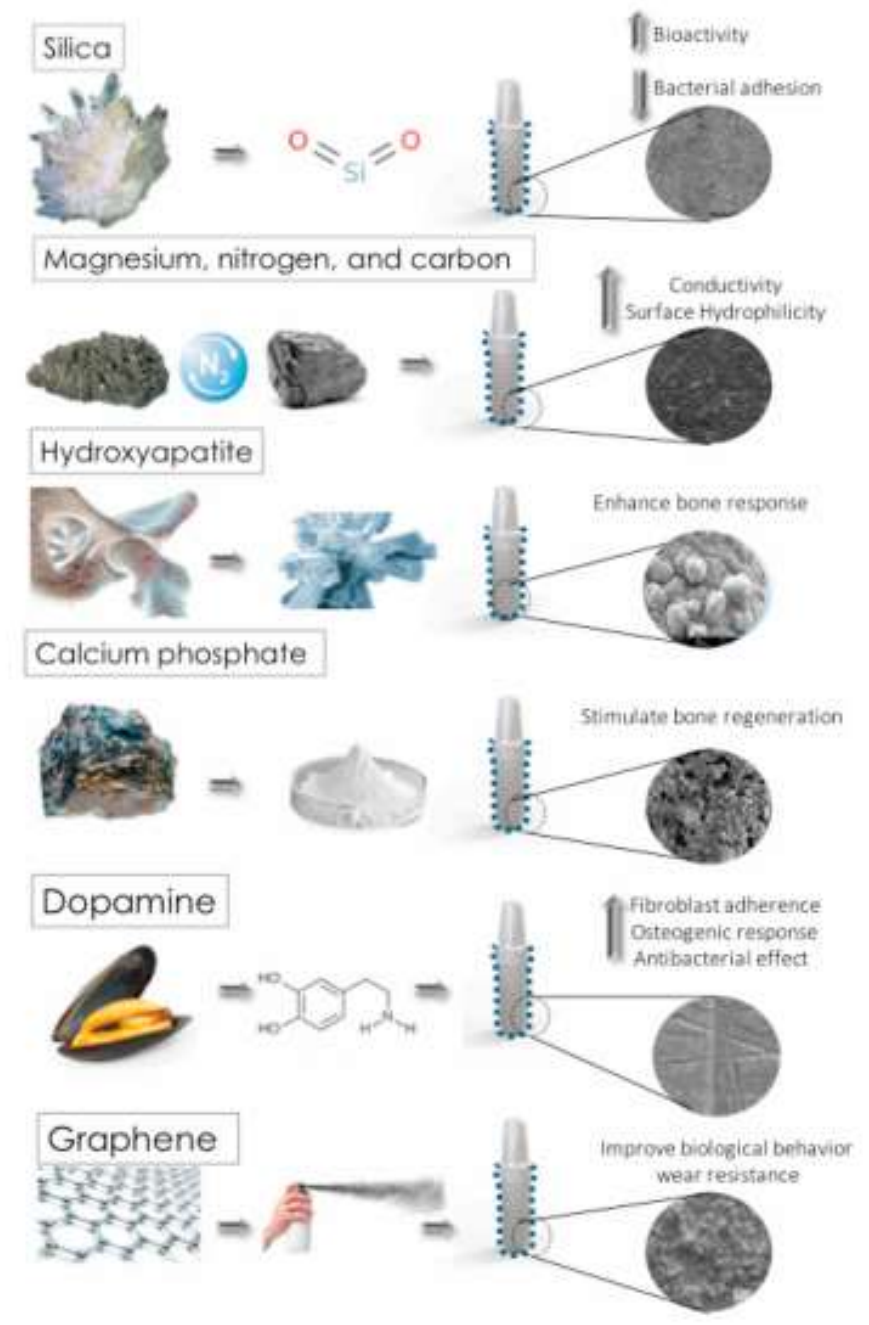

Fonte: F.H. Schünemann et al. (2019).

Apesar da necessidade de mais estudos a longo prazo, as alterações sobre a superfície da zircônia, promovendo uma aceleração na proliferação óssea e consequentemente permitindo um carregamento em menor tempo, associado as propriedades mecânicas, estética e menor adesão bacteriana, fazem desses implantes uma alternativa viável na reabilitação oral. 


\section{Discussão}

Os tratamentos de superfície, tem o objetivo de melhorar e/ou acelerar a osseointegração, que são de grande relevância em casos de tecido ósseo de baixa qualidade e pacientes com comprometimento sistêmico que indicariam uma necessidade de melhorar a estimulação da formação óssea nos processo iniciais de cicatrização (Bernardes et al., 2012). A hidrofilicidade e molhabilidade são características que levam o implante a alcançar esses objetivos (Karthigeyan et al., 2019), pois promovem as interações iniciais entre a superfície e o coágulo sanguíneo, sendo relevante para o processo cicatricial e osseointegração (Rupp et al., 2014). Além disso, a presença de rugosidades entre 0,5 e $2 \mu \mathrm{m}$, apresentam resultados mais favoráveis com resposta tecidual positiva. Segundo Bezerra et al., os tratamentos com jateamento de micropartículas, ataque ácido e anodização são os que atingem esses resultados. Ainda, afirmam que rugosidades superiores a $2 \mu \mathrm{m}$, aumentam o risco de contaminação bacteriana e consequentemente o desenvolvimento de peri-implantite (Bezerra et al., 2015).

A relação da superfície do implante com a formação de biofilme oral, é mais relevante do que o material do implante, pois superfícies rugosas tendem a acumular mais placa do que as lisas. Segundo Bermejo et al., as superfícies com rugosidades moderadas apresentam um maior acúmulo de placa e maior número de bactérias patogênicas do que aquelas com mínimas rugosidades (Bermejo et al., 2019). No entanto, Saulacic e Schaller, afirmam que a superfície rugosa não tem o potencial de promover a peri-implantite (Saulacic \& Schaller, 2019), já que a doença peri-implantar é multifatorial e deve-se levar em consideração a quantidade e qualidade do biofilme oral, higienização do paciente, condições sistêmicas, exposição do implante, entre outros (Lindhe et al., 2008; Romanos et al., 2015).

Com relação a hidrofilia e influência de nanoestruturas, Wennerberg et al., afirmaram que a osseointegração é influenciada pela capacidade de umedecimento e que superfícies super hidrofílicas, demonstram uma resposta óssea mais consistente quando comparadas a superfícies hidrofóbicas. A taxa de sobrevivência encontrada em implantes com superfícies tratadas com plasma spray de titânio (hidrofóbica), demonstraram maior probabilidade de falhas do que as superfícies anodizadas (hidrofílica). As superfícies anodizadas são promissoras e ainda podem ser encontradas sobre a superfície do titânio e da zircônia (Wennerberg \& Albrektsson, 2009).

Em relação ao processo de osseointegração, a literatura é clara em afirmar que o principal objetivo dos tratamentos está em acelerar o processo inicial de cicatrização, permitindo assim um carregamento protético em menor tempo. Carvalho et al. verificaram que há pouca diferença clínica e histológica entre os implantes após o carregamento (Carvalho et al, 2009). Assim como, Wannerberg et al., que encontraram resultados parecidos com as superfícies SLA e SLActive ${ }^{\circledR}$ (jateamento associado ao ataque-ácido e embalado em solução de $\mathrm{NaCl}$ 0,9\%), quando observaram que elas se nivelam em 6 semanas, apesar da resposta celular e do tecido ósseo serem mais acelerados durante a fase precoce de cicatrização na superfície SLActive ${ }^{\circledR}$ (Wennerberg et al., 2014). Os mesmos resultados foram encontrados no estudo de Soares et al., onde alterações estatisticamente significativas foram observadas quando a variável tempo foi analisada (pós-operatório, 15 dias e 30 dias). Entretanto, não houve diferenças quando a variável eram os diferentes tratamentos de superfície nos implantes. O efeito da alteração de energia superficial (molhabilidade) não apresentou diferenças estatísticas nas relações de contato entre ossoimplante (BIC - Bone Implant Contact) e na fração de ocupação de área óssea (BAFO - Bone Area Fraction Occupancy) (Soares et al., 2015). Assim como em um estudo realizado por Pebé et al, que analisou três tipos de tratamento de superfície (usinada, jateada e ataque ácido), e constatou que não houve diferenças no percentual de BIC, mas que implantes tratados com ácido apresentaram uma maior resistência ao torque do que os implantes jateados ou usinados (Pebé et al., 1997).

Quando comparados os resultados de osseointegração entre implantes de titânio com implantes de zircônia, ambos com superfícies tratadas, Kubasiewicz-Ross et al., apresentaram bons resultados de osseointegração em todos os implantes. Os resultados foram avaliados após 12 semanas da cirurgia, e o BIC foi verificado separadamente conforme a região do implante 
(pescoço, roscas e ápice). Concluíram que os implantes de zircônia, são uma excelente opção para reabilitações, por apresentarem resultados satisfatórios em relação aos implantes de titânio (Kubasiewicz-Ross et al., 2018). Bons resultados em relação a sobrevida de implantes de zircônia com diferentes tratamentos de superfície foram demonstrados por Oliva et al., quando acompanharam por 5 anos, 831 implantes e verificaram uma taxa média de sobrevivência de $95 \%$. Os implantes com superfície tratada por ataque ácido, obtiveram os melhores resultados, além da sondagem peri-implantar ter permanecido entre 2 e $3 \mathrm{~mm}$ (Oliva et al., 2010). No entanto, estudos recentes como o de Hanawa em 2020, concluiu que o titânio ainda é superior em propriedades mecânicas e na osseointegração, quando comparado a zircônia. Entretanto, em relação a adesão bacteriana, a zircônia é superior ao titânio, sugerindo que seja adequada para ser utilizada em abutments. Segundo o autor, ambos os materiais apresentam propriedades semelhantes de adesão aos tecidos moles (Hanawa, 2020). Sadowski, apresenta em seu estudo alguns problemas relacionados ao titânio como a tribocorrosão devido ao contato do titânio com flúor ou baixo ph salivar, o que pode gerar a liberação de partículas e consequentemente levar a reações inflamatórias, perda óssea e perda do implante. Outro ponto levantado pelo autor é a alergenicidade ao titânio de apenas 0,6\%, que apesar de ser uma taxa baixa, seria mais uma indicação ao uso de implantes em zircônia (Sadowsky, 2020).

Em relação ao uso de implantes de zircônia, Hochscheidt et al., afirmam que a cerâmica Y-TZP (zircônia tetragonal policristalina estabilizada com ítrio), apresenta ótimas propriedades biomecânicas, estabilidade química, radiopacidade, biocompatibilidade e assim, um elevado potencial de osseointegração. Essas propriedades associadas a uma característica de menor adesão bacteriana, apresenta uma vantagem quando se analisa a sobrevivência do implante e a relação aos tecidos moles peri-implantares (Hochscheidt et al., 2012). Em um estudo experimental recente, realizado em mandíbulas de cachorros, que avaliou radiograficamente a perda óssea peri-implantar induzida por ligadura em torno de implantes de titânio (Ti-SLA) e zircônia $\left(\mathrm{ZrO}_{2}\right.$-ZLA) carregados, concluiu que houve redução significativa na inflamação e perda óssea peri-implantar ao redor dos implantes de $\mathrm{ZrO}_{2}$-ZLA em comparação com os implantes de Ti-SLA, após 8 semanas de progressão ativa (com ligaduras) e 16 semanas de progressão espontânea (sem ligaduras) (Roehling, Gahlert, et al., 2019). Já em uma revisão sistemática, foram encontrados dados que demonstram uma capacidade similar de integração de tecidos moles e duros entre os implantes de zircônia e titânio. Apesar disso, o titânio tende a mostrar um processo de osseointegração inicial mais rápido quando comparado a zircônia (Roehling, Schlegel, et al., 2019).

As modificações de superfície podem deixar a zircônia com rugosidades comparáveis à superfície de Ti tratada, mas a resistência mecânica do titânio, ainda é superior à zircônia. As pesquisas são promissoras e vem progredindo, com o intuito de melhorar as propriedades da zircônia, principalmente em relação aos aspectos morfológicos, bioativos e até antimicrobiano (Figura 2), para assim acelerar e melhorar o processo de proliferação e diferenciação celular, consequentemente levando a reparação e osseointegração (Schünemann et al., 2019).

\section{Conclusão}

Os tratamentos de superfície se mostraram eficazes no processo de aceleração da osseointegração, tanto em titânio quanto em zircônia, permitindo um carregamento em tempos menores. Esse processo está intimamente ligado aos níveis de hidrofilicidade e molhabilidade que os tratamentos de superfícies podem gerar. A qualidade óssea, condições sistêmicas do paciente e carregamento pré planejado podem ser determinantes na escolha do tratamento de superfície adequado para a osseointegração.

Apesar de promissores, estudos longitudinais a longo prazo, que avaliem a sobrevivência in vivo, tanto no aspecto mecânico quanto no biológico, ainda são necessários nos casos de implantes de zircônia e seus tratamentos de superfície.

\section{Referências}


Abe, Y., Kokubo, T., \& Yamamuro, T. (1990). Apatite coating on ceramics, metals and polymers utilizing a biological process. Journal of Materials Science: Materials in Medicine, 1(4), 233-238.

Albrektsson, T., Brånemark, P.-I., Hansson, H.-A., \& Lindström, J. (1981). Osseointegrated Titanium Implants: Requirements for Ensuring a Long-Lasting, Direct Bone-to-Implant Anchorage in Man. Acta Orthopaedica Scandinavica, 52(2), 155-170.

Albrektsson, T., Branemark, P.-I., \& Zarb, G. A. (1985). Bone Tissue Response. In Tissue-Integrated Prostheses, Osseointegration in Clinical Dentistry (pp. 129-143). Quintessence Publishing Company.

Albrektsson, Tomas, \& Wennerberg, A. (2019). On osseointegration in relation to implant surfaces. Clinical Implant Dentistry and Related Research, 21(S1), $4-7$.

Barfeie, A., Wilson, J., \& Rees, J. (2015). Implant surface characteristics and their effect on osseointegration. British Dental Journal, $218(5)$, E9-E9.

Berardi, D., De Benedittis, S., Scoccia, A., Perfetti, G., \& Conti, P. (2011). New laser-treated implant surfaces: A histologic and histomorphometric pilot study in rabbits. Clinical \& Investigative Medicine, 34(4), 202.

Bermejo, P., Sánchez, M. C., Llama-Palacios, A., Figuero, E., Herrera, D., \& Sanz Alonso, M. (2019). Biofilm formation on dental implants with different surface micro-topography: An in vitro study. Clinical Oral Implants Research, 30(8), 725-734.

Bernardes, S. R., Claudino, M., \& Sartori, I. A. M. (2012). Relevância clínica do tratamento de superfície de implantes dentários. Jornal Ilapeo, 06(02), 6574 .

Bezerra, F. J. B., Pessoa, R. S., \& Zambuzzi, W. F. (2015). Carregamento funcional imediato ou precoce de implantes com câmara de cicatrização e nanosuperfície: estudo clínico prospectivo longitudinal. Innov Implant J, Biomater Esthet, 9(2/3), 12-7.

Bormann, K.-H., Gellrich, N.-C., Kniha, H., Dard, M., Wieland, M., \& Gahlert, M. (2012). Biomechanical evaluation of a microstructured zirconia implant by a removal torque comparison with a standard Ti-SLA implant. Clinical Oral Implants Research, 23(10), 1210-1216.

Carvalho, B. M., Pellizer, E. P., Moraes, S. L. D., Falcón-Antenucci, R. M., \& Ferreira Jr, J. S. (2009). Tratamentos de superfície nos implantes dentários / Surface treatments in dental implants. Rev. Cir. Traumatol. Buco-Maxilo-fac., 9(1), 123-130.

Chambrone, L., Shibli, J. A., Mercúrio, C. E., Cardoso, B., \& Preshaw, P. M. (2015). Efficacy of standard (SLA) and modified sandblasted and acid-etched (SLActive) dental implants in promoting immediate and/or early occlusal loading protocols: A systematic review of prospective studies. Clinical Oral Implants Research, 26(4), 359-370.

Costa, L. J., Souza, E. T., Lucena, F. L., \& Souza, R. C. V. (2015). Superfície de implantes de titânio e sua capacidade de estímulo na formação óssea: Uma revisão de literatura. Odontol. Clín.-Cient. 14(4), 797-800.

Dagher, M., Mokbel, N., Jabbour, G., \& Naaman, N. (2014). Resonance Frequency Analysis, Insertion Torque, and Bone to Implant Contact of 4 Implant Surfaces: Comparison and Correlation Study in Sheep. Implant Dentistry, Publish Ahead of Print.

Degidi, M., Nardi, D., \& Piattelli, A. (2012). 10-Year Follow-Up of Immediately Loaded Implants with TiUnite Porous Anodized Surface: 10-Year Follow-Up of TiUnite Surface. Clinical Implant Dentistry and Related Research, 14(6), 828-838.

Esposito, M., Ardebili, Y., \& Worthington, H. V. (2014). Interventions for replacing missing teeth: Different types of dental implants. Cochrane Database of Systematic Reviews, (7).

Gaggl, A., Schultes, G., Müller, W. D., \& Kärcher, H. (2000). Scanning electron microscopical analysis of laser-treated titanium implant surfaces-A comparative study. Biomaterials, 21(10), 1067-1073.

Gahlert, M., Gudehus, T., Eichhorn, S., Steinhauser, E., Kniha, H., \& Erhardt, W. (2007). Biomechanical and histomorphometric comparison between zirconia implants with varying surface textures and a titanium implant in the maxilla of miniature pigs. Clinical Oral Implants Research, 18(5), 662-668.

Gahlert, M., Kniha, H., Weingart, D., Schild, S., Gellrich, N. C., \& Bormann, K. H. (2016). A prospective clinical study to evaluate the performance of zirconium dioxide dental implants in single-tooth gaps. Clinical Oral Implants Research, 27(12), e176-e184.

Gahlert, M., Roehling, S., Sprecher, C. M., Kniha, H., Milz, S., \& Bormann, K. (2012). In vivo performance of zirconia and titanium implants: A histomorphometric study in mini pig maxillae: In vivo performance of zirconia and titanium implants. Clinical Oral Implants Research, 23(3), $281-286$.

Galan Jr, J., \& Vieira, R. M. (2013). Caracterização das superfícies de implantes dentais comerciais em MEV/EDS. Rev. Bras. Odontol., 70(01), 68-79.

Gil, L. F., Marin, C., Teixeira, H., Marão, H. F., Tovar, N., Khan, R., Bonfante, E. A., Janal, M., \& Coelho, P. G. (2016). The effect of controlled microrobotized blasting on implant surface texturing and early osseointegration. Journal of Biomaterials Applications, 30(7), 900-907.

Mastrangelo, F., Fioravanti, G., Quaresima, R., Vinci, R., \& Gherlone, E. (2011). Self-Assembled Monolayers (SAMs): Which Perspectives in Implant Dentistry? Journal of Biomaterials and Nanobiotechnology, 02(05), 533-543.

Neto, U. G. G., \& de Araújo Bacelar, S. M. (2019). Implantes dentários com superfície tratada: revisão de literatura. Brazilian Journal of Implantology and Health Sciences, 1(4), 69-83.

Hafezeqoran, A., \& Koodaryan, R. (2017). Effect of Zirconia Dental Implant Surfaces on Bone Integration: A Systematic Review and Meta-Analysis. BioMed Research International, 2017, 1-12.

Hanawa, T. (2020). Zirconia versus titanium in dentistry: A review. Dental Materials Journal, 39(1), 24-36. 
Hochscheidt, C. J., Alves, E. D. M., Bernardes, L. A. B., Hochscheidt, M. L., \& Hochscheidt, R. C. (2012). Zirconia dental implants: An alternative for today or for the future? (Part II). Dental Press Implantology, 6(4), 114-124.

Jemat, A., Ghazali, M. J., Razali, M., \& Otsuka, Y. (2015). Surface Modifications and Their Effects on Titanium Dental Implants. BioMed Research International, 2015, 1-11.

Karthigeyan, S., Ravindran, A., Bhat, R. R., Nageshwarao, M., Murugesan, S., \& Angamuthu, V. (2019). Surface modification techniques for zirconia-based bioceramics: A review. Journal of Pharmacy And Bioallied Sciences, 11(6), 131.

Kubasiewicz-Ross, P., Hadzik, J., \& Dominiak, M. (2018). Osseointegration of zirconia implants with 3 varyingsurface textures and a titanium implant:A histological and micro-CT study. Advances in Clinical and Experimental Medicine, 27(9), 1173-1179.

Lindhe, J., Meyle, J., \& on behalf of Group D of the European Workshop on Periodontology. (2008). Peri-implant diseases: Consensus Report of the Sixth European Workshop on Periodontology. Journal of Clinical Periodontology, 35, 282-285.

Misch, C. E. (2011). Implantes dentais: Contemporâneos. Elsevier

Oliva, J., Oliva, X., \& Oliva, J. D. (2010). Five-year success rate of 831 consecutively placed Zirconia dental implants in humans: A comparison of three different rough surfaces. The International Journal of Oral \& Maxillofacial Implants, 25(2), 336-344.

Pebé, P., Barbot, R., Trinidad, J., Pesquera, A., Lucente, J., Nishimura, R., \& Nasr, H. (1997). Countertorque testing and histomorphometric analysis of various implant surfaces in canines: A pilot study. Implant Dentistry, 6(4), 259-265.

Richardson, D. J., Nilsson, J., \& Clarkson, W. A. (2010). High power fiber lasers: Current status and future perspectives [Invited]. Journal of the Optical Society of America B, 27(11), B63.

Roccuzzo, M., \& Wilson Jr., T. G. (2008). A Prospective Study of 3 Weeks' Loading of Chemically Modified Titanium Implants in the Maxillary Molar Region: 1-year Results. Int J Oral Maxillofac Implants, 24(1),65-72.

Roehling, S., Astasov-Frauenhoffer, M., Hauser-Gerspach, I., Braissant, O., Woelfler, H., Waltimo, T., Kniha, H., \& Gahlert, M. (2017). In Vitro Biofilm Formation on Titanium and Zirconia Implant Surfaces. Journal of Periodontology, 88(3), 298-307.

Roehling, S., Gahlert, M., Janner, S., Meng, B., Woelfler, H., \& Cochran, D. (2019). Ligature-Induced Peri-implant Bone Loss Around Loaded Zirconia and Titanium implants. The International Journal of Oral \& Maxillofacial Implants, 34(2), 357-365.

Roehling, S., Schlegel, K. A., Woelfler, H., \& Gahlert, M. (2019). Zirconia compared to titanium dental implants in preclinical studies-A systematic review and meta-analysis. Clinical Oral Implants Research, 30(5), 365-395.

Romanos, G. E., Javed, F., Delgado-Ruiz, R. A., \& Calvo-Guirado, J. L. (2015). Peri-implant Diseases. Dental Clinics of North America, 59(1), $157-178$.

Rosifini, M. C., de Carvalho, S. F., Roberto, C., de Magalhães, A. P., \& Rosifini, A. P. (2011). Tratamento de superfície de implantes dentparios: SBF. 32(2), $38-43$.

Rupp, F., Gittens, R. A., Scheideler, L., Marmur, A., Boyan, B. D., Schwartz, Z., \& Geis-Gerstorfer, J. (2014). A review on the wettability of dental implant surfaces I: Theoretical and experimental aspects. Acta Biomaterialia, 10(7), 2894-2906.

Saulacic, N., \& Schaller, B. (2019). Prevalence of Peri-Implantitis in Implants with Turned and Rough Surfaces: A Systematic Review. Journal of Oral and Maxillofacial Research, 10(1).

Sadowsky, S. J. (2020). Has zirconia made a material difference in implant prosthodontics? A review. Dental Materials, 36(1), 1-8. https://doi.org/10.1016/j.dental.2019.08.100

Schünemann, F. H., Galárraga-Vinueza, M. E., Magini, R., Fredel, M., Silva, F., Souza, J. C. M., Zhang, Y., \& Henriques, B. (2019). Zirconia surface modifications for implant dentistry. Materials Science and Engineering: C, 98, 1294-1305.

Sener-Yamaner, I. D., Yamaner, G., Sertgöz, A., Çanakçi, C. F., \& Özcan, M. (2017). Marginal Bone Loss Around Early-Loaded SLA and SLActive Implants: Radiological Follow-Up Evaluation Up to 6.5 Years. Implant Dentistry, 26(4), 592-599.

Sennerby, L., Dasmah, A., Larsson, B., \& Iverhed, M. (2005). Bone Tissue Responses to Surface-Modified Zirconia Implants: A Histomorphometric and Removal Torque Study in the Rabbit. Clinical Implant Dentistry and Related Research, 7(s1), s13-s20.

Shi, Q., Qian, Z., Liu, D., \& Liu, H. (2017). Surface Modification of Dental Titanium Implant by Layer-by-Layer Electrostatic Self-Assembly. Frontiers in Physiology, 8, 574 .

Silva, F. L. e, Rodrigues, F., Pamato, S., \& Pereira, J. R. (2016). Tratamento de superfície em implantes dentários: Uma revisão de literatura. Revista da Faculdade de Odontologia - UPF, 21(1).

Smeets, R., Stadlinger, B., Schwarz, F., Beck-Broichsitter, B., Jung, O., Precht, C., Kloss, F., Gröbe, A., Heiland, M., \& Ebker, T. (2016). Impact of Dental Implant Surface Modifications on Osseointegration. BioMed Research International, 2016, 1-16.

Soares, P. B. F., Moura, C. C. G., Claudino, M., Carvalho, V. F., Rocha, F. S., \& Zanetta-Barbosa, D. (2015). Influence of Implant Surfaces on Osseointegration: A Histomorphometric and Implant Stability Study in Rabbits. Brazilian Dental Journal, 26(5), 451-457.

de Souza, A. S., Colombo, L. T., Hadad, H., Santos, A. F. P., da Silva, R. C., Poli, P. P., \& de Carvalho, P. S. P. (2020). Bone regeneration around implants with modified surface by acid conditioning with the fluoride ions deposition. Journal of Osseointegration, 12(3), 222-228.

Steinemann, S. G. (1998). Titanium? The material of choice? Periodontology 2000, 17(1), 7-21. 
Research, Society and Development, v. 10, n. 9, e37810918197, 2021

(CC BY 4.0) | ISSN 2525-3409 | DOI: http://dx.doi.org/10.33448/rsd-v10i9.18197

Velasco-Ortega, E., Ortiz-García, I., Jiménez-Guerra, A., Monsalve-Guil, L., Muñoz-Guzón, F., Perez, R. A., \& Gil, F. J. (2019). Comparison between Sandblasted Acid-Etched and Oxidized Titanium Dental Implants: In Vivo Study. International Journal of Molecular Sciences, $20(13), 3267$.

Wennerberg, A., \& Albrektsson, T. (2009). Effects of titanium surface topography on bone integration: A systematic review. Clinical Oral Implants Research, $20,172-184$.

Wennerberg, A., Albrektsson, T., \& Lausmaa, J. (1996). Torque and histomorphometric evaluation of c.p. Titanium screws blasted with 25- and 75-micronssized particles of A12O3. Journal of Biomedical Materials Research, 30(2), 251-260.

Wennerberg, A., Jimbo, R., Stübinger, S., Obrecht, M., Dard, M., \& Berner, S. (2014). Nanostructures and hydrophilicity influence osseointegration: A biomechanical study in the rabbit tibia. Clinical Oral Implants Research, 25(9), 1041-1050. 